\title{
A Conceptual Basis for Library Effectiveness
}

\begin{abstract}
The concept of library effectiveness finds its roots in systems theory. This approach explicitly recognizes the existence of multiple criteria by which the effectiveness of a given library may be judged and the need for a new kind of model to conceptualize the components of the effective library better. One solution that minimizes the many difficulties to viewing effectiveness criteria simultaneously is to view effectiveness as a process of converting input to output rather than some end result.
\end{abstract}

M ing effectiveness is a basic responsibility of library management. However, there is a notable lack of agreement on what the concept of effectiveness means.

One major group sees library effectiveness as the achievement of goals. ${ }^{1}$ A second major group measures effectiveness by the efficient use of resources in optimizing performance. ${ }^{2} \mathrm{~A}$ third major group defines effectiveness in terms of the personnel within the library and the satisfaction that they obtain from their jobs. ${ }^{3} \mathrm{~A}$ fourth major group equates effectiveness with user satisfaction. ${ }^{4}$

In short, while there is general consent that all libraries should attempt to be effective, the criteria for appraisement remain unclear.

In light of the variety of ways in which administrators and researchers perceive library effectiveness, it should also be noted that there is equal disagreement over the best strategy for becoming effective.

One significant reason for this lack of agreement stems from the narrow focus that many people apply to the effectiveness construct. As already noted, many define effectiveness in terms of a single criterion (user satisfaction or optimal efficiency, for example). But it is difficult to conceive of a li-

Rosemary Ruhig Du Mont is assistant professor, College of Library Science, University of Kentucky, Lexington. brary that would survive for long if it pursued user satisfaction to the exclusion of employee needs or if it concentrated on efficiency to the exclusion of user satisfaction. Libraries as organizations typically pursue multiple (and often conflicting) objectives; and these objectives tend to differ from library to library according to the nature of the community within which the library operates and the nature of the services it is supposed to offer.

A second reason for the absence of concurrence on the nature of effectiveness arises from the vagueness of the concept. One might assume that it is relatively easy to identify the various criteria for judging effectiveness. As a matter of fact, such criteria tend to be difficult to establish; in reality they depend largely on who is formulating the criteria, for what reason, and within what specific frame of reference.

In a recent paper, Du Mont and Du Mont categorized relevant facets of effectiveness identified by researchers that could serve as useful evaluating criteria. $^{5}$ They synthesized four major approaches to assessing library effectiveness. (Figure 1 summarizes these approaches.)

As figure 1 reveals, most major criteria of library effectiveness considered by researchers are related to library input, e.g., staff, money, materials, or services. There is only limited consideration of output, i.e., the effect of library service on its public. 


\section{MAJOR APPROACHES TO VIEWING LIBRARY EFFECTIVENESS}

1. Primary emphasis on physical input (number of staff, amount of money, etc.)

As perceived by agents in the environment (accrediting agencies, funding agencies, etc.) who determine how much financial support the library does need to be viable

As perceived by agents in the environment (professional library associations) who are interested both in what the library does need as stated in established standards, and what it could use as stated in established goals

2. Primary emphasis on the organizational dynamics of the library (the relationship between the library staff and the formal library organization)

As perceived by individual staff, including subjective characterizations of needed library input for staff development

As perceived by the library, including subjective characterizations of needed staff input for library development

3. Primary emphasis on library inputs (materials and services) as they are perceived by patrons Including characterizations made by patrons of how well the library is equipped to serve them

Including characterizations made by the library describing how well the user is being supplied with materials and services

4. Primary emphasis on library input (materials and services) as they affect elements within the society as a whole

As perceived by the library as an organization which wishes to serve that society

Source: Rosemary Ruhig Du Mont and Paul F. Du Mont, "Measuring Library Effectiveness: A Review and an Assessment," in Michael Harris, ed., Adcances in Librarianship 9:129 (New York: Academic Press, 1979).

Fig. 1

Major Approaches to Viewing Library Effectiveness

\section{PROBLEMS IN ASSESSMENT}

The lack of agreement on the significance of various techniques poses a serious problem both for library administrators and for analysts of the library as an organization; it makes it difficult, if not impossible, to evaluate a library's success or failure adequately. This inability to concur on meaningful criteria to be used across the library spectrum results, in part, from ignoring a number of problems that must be solved before one can arrive at more meaningful approaches to assessing library effectiveness. These problems are delineated in the following questions. ${ }^{6}$

1. Is there any such thing as library effectiveness? The very abstractness of much of the discussion that goes on in the name of library effectiveness can lead one to the conclusion that the concept of effectiveness has little applicability to the actual working library. Those who believe that effectiveness is a viable concept need an explicit definition of the effective library.

2. How stable-consistently valid-are the assessment criteria? The Du Mont and Du Mont study pointed out that a time horizon is a significant component in assessment. ${ }^{7}$ Perceptions of library effectiveness will vary over time. For example, in the short run the effective library may be one that is able to supply the current library patron with the materials he or she demands. Over time, however, if the library continues to fulfill only the demands of library patrons and makes no attempt to also fulfill unverbalized needs, the library may be considered to be ineffective.

Clearly, most criteria of library effectiveness do not represent permanent indications of library success. In fact, it is the changing nature of many effectiveness criteria that has led some library investigators to suggest that adaptability or flexibility represents a key variable in any model of effectiveness. ${ }^{8}$

3. Which time perspective is most appropriate in assessment? A major problem for a library administrator is to decide how best to allocate available resources between short-range and long-term purposes so that both receive sufficient support. In terms of assessment of resource allocation, the question becomes one of determining which time perspective to take in judging effectiveness. 
It must be noted that what is effective in the short run may not be appropriate over the long term. For example, if day-to-day activities (a short-range approach) consume so much of a library's resources that little is left over for planning for the future, the library's outmoded services and materials may threaten its very survival.

4. Are the assessment criteria related positively to each other? Most approaches to assessing library effectiveness rely on a series of relatively discrete criteria (for example, workload indicators, physical standards, job satisfaction, etc.). However, it is difficult to judge the effectiveness of libraries using a number of these criteria simultaneously, because many of the criteria compete with one another.

Consider, for instance, a library that uses efficiency and user satisfaction as two of its criteria for effectiveness. The standard of efficiency can cause the library to purchase only high-demand materials and to rely on a centralized purchasing and storage facility for the remaining items. Such an effort can lead to reduced user satisfaction, as many items demanded will not be available on the library shelves when the user wants them.

On the other hand, it is possible to increase user satisfaction by yielding to every user demand for increased library materials in the local library, but at the price of greatly reduced efficiency. Thus while the use of multiple evaluation criteria adds breadth to any assessment attempt, it also adds complexity to the assessment process.

5. How useful are the assessment criteria? This question relates to the measurement of library effectiveness. Do the various criteria used to measure the effectiveness of library performance actually do so?

In point of fact, libraries tend to measure performance in terms of "proxy measures" easily quantifiable outputs such as circulation, that are assumed to say something about the effectiveness of library operations. Such measures obviously have their limitations, the most basic one being the lack of relevance between the "proxy" and the effectiveness of the program or process the "proxy" supposedly represents.

6. How do effectiveness criteria help us understand library dynamics? How useful is the effectiveness construct? What purposes are served by the process of evaluating effectiveness? Does it provide insight into the dynamics of library operations? Does it help in the making of predictions for the future of the library? Unless a model of library effectiveness facilitates a better understanding of library structure, processes, and behavior, it has little value for library analysts.

7. At which level should effectiveness be assessed? Library administrators face the problem of the level at which to assess effectiveness. Logic might suggest evaluating effectiveness on a library-wide basis. Such an approach may seem overwhelming, however, due to the complexity of the library as an organization.

For example, an examination of various processes within the library are likely to show that certain units are more successful or effective than others. The existence of such differences complicates any attempts to draw firm conclusions of the effectiveness of a given library. Yet, if understanding of the library as an organization is to be increased, models of effectiveness must be developed that enable library practitioners, to the greatest extent possible, to identify the nature of the relationships between the individual processes and the behavior of the library as a whole.

Even a cursory examination of the problems posed by these questions reveals the complexity of the subject. If library administrators are to be able to reduce their dependence on simplistic measuring techniques for evaluating effectiveness, a framework must be provided for analysis that integrates the various elements within and without the library, allowing the library to be viewed as the sum of its parts.

\section{WHAT IS LIBRARY EFFECTIVENESS?}

If the notion is accepted that libraries are unique and pursue divergent goals reflective of their own unique environment, then one must move away from a general conceptual definition of library effectiveness toward a more operational one. Thus it appears to be useful to develop a contingency approach and to define library effectiveness in terms of each library's level of ability in responding to its own unique situational and environmental constraints. Viewed from this 
perspective, effectiveness is perceived through the examination of process rather than the end result.

Such a view requires elaboration. In essence, the contingency approach stresses that contingent factors such as type of clientele or size of book stock have some direct influences on levels of success.

There may be, for example, economies available to those purchasing multiple copies for a large library system that are not available to its smaller counterpart. "It is assumed that a set of structured administrative arrangements consciously adapted to the tasks that are to be done, to the scale of the total operation, to its overall complexity, and to the pressures of change being encountered will themselves act to promote a higher level of effectiveness than will a structure ill-suited to those contingencies." 9

The important point is that there are usually conflicting demands inherent in attempts to secure an effective match between a library's internal contingencies and the contingencies it faces in the environment, and each demand has its own potential measures of effectiveness. The contingency approach makes it possible to identify simultaneously many managerial and organizational factors that are related to library effectiveness. ${ }^{10}$

Inherent in such a view is the notion that effectiveness can best be perceived by viewing the library as a system. Systems theory suggests that understanding the library can come only through integrating knowledge about it from a variety of sources; i.e. structure, knowledge, techniques, equipment, facilities, users, personnel, etc., are all inextricably linked and to consider one means to consider them all. Additionally, any library, in judging its effectiveness, must consider the library/environment interface. Finally, a time horizon must be considered in examining the effectiveness of any given library.

\section{A MODEL AND SUPPORTING \\ PROPOSITIONS FOR CONCEPTUALIZING LIBRARY EFFECTIVENESS}

The systems model that is proposed in figure 2 emphasizes three major aspects:

1. the notion that achieving library effectiveness is a dynamic ongoing process;

2. the perception that inputs and outputs are likely to change over time;

3 . the outlook that individual human behavior (both within and out of the library) affects perception of library success or failure.

These aspects are different in each library and reflect the notion that it is unlikely that any single definition of effectiveness will be applicable to more than one individual library. Comparisons across libraries could be made with respect to one contingent factor (clientele, collection, etc.). However, it is unlikely that the systems models of libraries developed through use of the model presented here will be comparable.

How then does the use of this model aid
Inputs

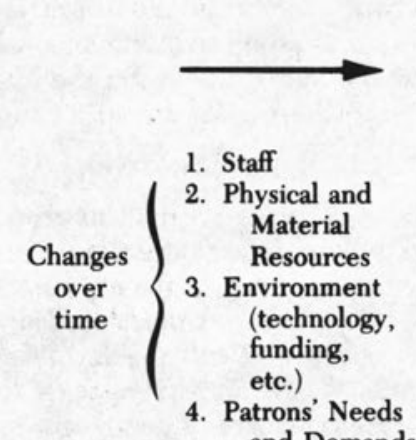

Outputs

Library

Processes/

Activities

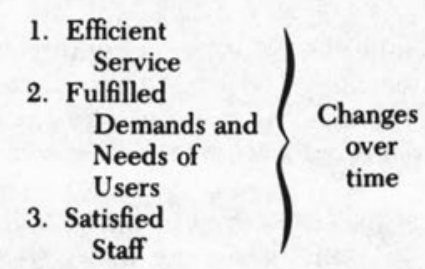

Fig. 2

A Systems Model of Library Effectiveness 
in the investigating of effectiveness? The model provides a practical (but complicated) set of guideposts for assessing various elements of an individual library's effectiveness.

Ways of viewing individual elements within the model and propositions supporting these views follow:

The first element is the individual library employee.

Proposition 1: Libraries that adopt forms of administrative structure consistent with the expectation and perceived needs of their personnel will tend to achieve higher levels of performance and be judged by their personnel as more effective.

This proposition is a cornerstone of the behavioral study of organizations. ${ }^{11}$ Library researchers in this area argue for structures and styles of management that secure a higher degree of commitment to the library from employees by more adequately meeting their expectations and needs. ${ }^{12}$

However, some qualification is in order. Not only do these perceived needs change over time, but it is also clear that different types of people do not have the same needs on their jobs. Thus one might look to research on the differing psychological needs of professional librarians and paraprofessionals, or the changing needs of new professionals who remain long on the job as ways of dealing with this element.

The second element is the library itself.

Proposition 2. Libraries' ability to adapt to, buffer, or level environmental change is inversely related to their dependence upon instinct, habit, or tradition. Libraries able to learn and to perform according to changing contingencies in the environment will tend to achieve higher levels of performance, i.e., be more effective.

The influence of the environment on organizations has been considered by a number of writers. ${ }^{13}$ Library/environment interface has been mentioned in this paper. ${ }^{14}$

This proposition expresses the fundamental argument for proving utility that has become a dominant cry among librarians. In order to do so, obtaining adequate resources (financial support as well as the more intangible emotional support) from the environ- ment becomes the logical short-term goal. Libraries that obtain such support are more likely to grow and adapt over the intermediate range of time and survive over the long haul. Detailed research on the survival instincts of libraries is yet forthcoming. What does happen to libraries over time? How do they change and respond to diversity? What does being a more successful library mean over the short range as well as the long term?

The third element is the individual library user.

Proposition 3. Libraries able to supply timely, relevant, and accessible service to all users will be considered more effective than those that do not.

Effort must be made to match conceptions of service to the needs and tastes of the particular user in question. Most librarians, when dealing with service to patrons, consider only the demands made by present-day users of libraries. Unverbalized needs of those users and the whole range of needs and demands of nonusers are generally not considered. Great care must be taken to consider all these categories of demands and needs in dealing with the concept of the effective library, not only as they relate to general concepts of library performance, but also as they relate to specific responses to individual users and potential users over time.

The fourth element is the society at large.

Proposition 4. In order to adapt to the changing external environment, one strategy for the library is to develop a systematic mechanism by which to measure the preferences of various groups for library services and the relative strengths of these groups to affect library welfare. This information can be incorporated into its decision-making strategies in such a manner that it maximizes social satisfaction against social expectations, sustains incentives for its funding agency to continue its support, and mobilizes its resources efficiently so that its traditional constituent groups, for example, employees and present patrons, are satisfied with its performance.

In supporting this proposition over a period of time, the library can actively seek to measure different groups' support for its ac- 
tions and also the behaviors of those groups as they affect the library. Such behaviors may range from no action, verbal support, letter writing to potential funding agencies, and the like, to actual library use. The library may seek to investigate the relations between a group's appraisals of the library's behavior and the group's actual use of the library. Perhaps, also, some measure of a group's attitude toward the library can be related to its evaluation of the library's actions.

The study of attitudes is useful because of its relevance to creating within the library an improved understanding of the ways in which the library's behavior affects reactions within the environment.

To date, there have not been many serious attempts to study group attitudes toward library use. ${ }^{15}$ The problems inherent in conducting such studies are great. That does not mean that an approach that is capable of analyzing the priorities of individuals, groups, or larger collections of groups should not be attempted. There is such a need to rank competing action alternatives of libraries; and to do so, the consideration of different group preferences over time is a necessity.

\section{IMPLICATIONS FOR LIBRARY MANAGEMENT}

Four propositions have been discussed, reflecting some of the components that make up the dimensions of library effectiveness. Although most library researchers at present select only one of the components in an examination of effectiveness, it is concluded that consideration of the process by which these components interrelate is needed to create an overall framework for the judging of library effectiveness.

The idea of a model of library effectiveness, emphasizing some kind of specific end results, is rejected. The question posed may be: "What results should we look for in assessing the effectiveness of any given library?" The answer is that the question itself is inappropriate. There is no general model of library effectiveness categorizing specific outcomes appropriate to all libraries. To study the effectiveness of a given library, one needs to establish a unique model reflecting the uniqueness of that library. This can be done by using the framework illustrated in figure 2 .

Let us assume we want to assess the effectiveness of a university library empirically. First, the identification of relevant inputs takes place. For example, the relevant user needs being served by the library have to be recognized. Recognition can be based on such criteria as (1) suitability of the user need, (2) the criticalness of serving that need, and (3) the degree to which a user group has formally organized to have its needs served.

We also need to identify the appropriate level of analysis of library processes. Let's assume, for example, that the distribution of new information to the users identified is a relevant process for the effective library. Do we measure the library's ability to distribute information, or do we examine the process in individual units of the library?

The resolution of the question comes from examining the activities of a number of public service departments in the library over time. The conclusion is reached that information distribution in various departments is different over time; thus the study of the effectiveness of this process can be made only on the department level. Output is also measured on a department level, not on a library-wide basis. The effectiveness of information distribution by the library as a whole is judged through the integrating of results from these individual levels.

The above illustration of the use of the systems model is brief because of space limitations. The basic point is that the model is not a picture of the effective library. Rather, it is a kind of outline for the administrator to complete. The appropriate inputs need to be identified, the significant processes and the levels at which they aggregate must be determined, and the appropriate outputs for these levels must be established.

The propositions stated in support of the model can aid in filling in this outline. The first draws attention to the desirability of a committed staff that participates in the setting of library goals. It supports the general position of research on motivation and reward by indicating that the performance of libraries is enhanced when personnel are granted a sizable personal stake in its development. 
The thrust of the second proposition is that the structure of the library is likely to influence its performance. Problems have to be worked out in the context of each library's own circumstances. Much examination needs to be done before deciding on the form of the library that is most appropriate.

First, the nature of present and future contingencies must be assessed. In other words, just what kind of institution is the library, what does it want to be in terms of scope of clientele, size, type of service, and so on?

Second, what are the organizational requirements imposed by relevant contingencies? For example, a large library will have particular problems of communication and coordination. What alternative organizational designs might satisfy these requirements?

Third, if different contingencies pose the dilemma of conflicting requirements, what policies could be formulated to modify the contingencies themselves? Some libraries, for example, that seek to broaden their scope of services or that seek to combine a successful new service with economies of a large scale, such as centralized technical processing, are finding that they can circumvent the size contingency by setting up small, internally flexible experimental service units or similar libraries within a library.

The important point is that there are usually several ways of securing an effective match between a library's internal organization and the contingencies it faces. This fact tends to be overlooked by those who share the present-day concern about the bureaucratization of libraries. A bureaucracy can be operated in different ways, depending upon its own unique circumstances. There are in most library situations various possibilities for increasing effectiveness, no matter what kind of contingencies are faced.

The third proposition emphasizes the fact that much more knowledge is needed on the nature of individual patron needs so that adequate systems can be designed that will satisfy those needs.

The fourth proposition points out the need for more political acumen on the part of librarians, an attribute necessary in the identification of the groups most likely to support various kinds of library service, so that libraries can survive over the long term.

Most libraries exist in a constantly fluctuating environment in which threats to survival and growth are relatively commonplace. Within such environments, library administrators must try to identify and use the various inputs at their disposal constructively in an effort to achieve outputs that meet up to the expectations of all those concerned with library performance. The process by which they do so, or fail to do so, is at the heart of the concept of library effectiveness.

\section{CONCLUSION}

In the previous discussion, a review of various approaches to perceiving library effectiveness has been made. Little homogeneity exists among the various approaches. This lack of consensus, in turn, results from the existence of at least seven problems inherent in the consideration of the concept of library effectiveness. In an effort to overcome these problems, a systems model of library effectiveness has been proposed.

The model described differs from previous models. Instead of specifying the criteria for effectiveness (for example, under what conditions is a library effective?), this model focuses on the process of being effective (for example, how are expectations satisfied at a given time for a given person to judge the library as effective?) It is argued that the actual criteria for evaluation vary depending on the particular expectations of the particular person (or group) in question.

It is stressed that the use of a systems model allows for the explicit recognition of the ways in which various organizational factors blend together to facilitate or inhibit activities concerned with library effectiveness. This perspective forces library administrators to use a more comprehensive approach in an examination of library performance, facilitating a broader vision of the nature of the effectiveness problem and on its possible solutions.

A general conclusion to be drawn from this discussion relates to the concept of ef- 
fectiveness as a continuous process rather than an end result. Library responsiveness to expectations is an unceasing task. In view of the changing nature of inputs, administrators have a continuing responsibility to recognize changes in the environment, to restructure available resources, to modify technologies, to develop employees, and so forth, in order to best employ the resources of the library to fulfill expectations that are themselves constantly changing.

\section{REFERENCES}

1. See, for example, Martha Boaz, "Evaluation of Special Library Service for Upper Management," Special Libraries 59:289-91 (Dec. 1969); Charles R. McClure, "The Planning Process: Strategies for Action," College $b$ Research Libraries 39:456-66 (Nov. 1978); F. W. Lancaster, The Measurement and Evaluation of Library Services (Washington, D.C.: Information Resources Pr., 1977), p.2-9; Morris Hamburg, Leonard E. Ramist, and Michael R. W. Bommer, "Library Objectives and Performance Measures and Their Use in Decision Making," Library Quarterly 42:107-28 (Jan. 1972); E. Evans, H. Borko, and P. Ferguson, "Review of Criteria Used to Measure Library Effectiveness," Bulletin of the Medical Library Association 60:102-10 (Jan. 1972); John R. Haak, "Goal Determination," in Ross Shimmon, ed., A Reader in Library Management (Hamden, Conn.: Linnet, 1976), p.83-96.

2. See, for example, Richard M. Dougherty, "The Human Side of Library Effectiveness," in Allan F. Hershfield and Morell D. Boone, eds., Approaches to Measuring Library Effectiveness: A Symposium (Syracuse, N.Y.: School of Library Science, Syracuse Univ., 1972), p.40-47; Ernest R. DeProspo and Ellen Altman, "Another Attempt at Measuring Public Library Effectiveness: Some Methodological Considerations," in ibid., p.14-30; Kenneth Beasley, "A Theoretical Framework for Public Library Measurement," in Herbert Goldhor, ed., Research Methods in Librarianship: Measurement and Evaluation (Champaign, Ill.: University of Illinois Graduate School of Library Science, 1968), p.2-13; R. H. Orr, "Measuring the Goodness of Library Services: A General Framework for Considering Quantitative Measures," Journal of Documentation 29:315-32 (Sept. 1973); Richard W. Trueswell, "User Circulation Satisfaction vs. Size of Holdings at Three Academic Libraries," College \& Research Libraries 30:204-13 (May 1969).

3. See, for example, Dougherty, "The Human Side of Library Effectiveness."

4. See, for example, Barry Totterdell and Jean
Bird, The Effective Library: Report of the Hillingdon Project on Public Library Effectiveness (London: The Library Association, 1976); Douglas L. Zweizig, "Measuring Library Use," Drexel Library Quarterly 13:315 (July 1977); F. W. Lancaster, Measurement and Evaluation, p.299-309; Timothy P. Hays and Concepcion S. Wilson, A Survey of Users and Non-users of Public Libraries in Region 6, North Carolina (Greensboro, N.C.: Piedmont Triad Council of Governments, 1974).

5. Rosemary Ruhig Du Mont and Paul F. Du Mont, "Measuring Library Effectiveness: A Review and an Assessment," in Michael Harris, ed., Advances in Librarianship 9:103-41 (New York: Academic Pr., 1979).

6. Such questions were first raised by Richard M. Steers, "When Is an Organization Effective? A Process Approach to Understanding Effectiveness," Organizational Dynamics 4:51-54 (Autumn 1976).

7. Du Mont and Du Mont, "Measuring Library Effectiveness," p.131.

8. See, for example, Larry Earl Bone, "The Public Library Goals and Objectives Movement: Death Gasp or Renaissance?" Library Journal 100:1283-86 (July 1975); Allen F. Hershfield, "Measuring Library Effectiveness: A Challenge to Library Educators: Introductory Remarks," in Hershfield and Boone, eds., Approaches to Measuring Library Effectiveness, p.7-13.

9. Du Mont and Du Mont, "Measuring Library Effectiveness," p. 132.

10. See, for example, the various contingencies identified in the model developed by John L. Davies, "Organizational Effectiveness and Corporate Management: The Implications for Libraries," in P. A. Thomas and Valerie A. Ward, eds., The Corporate Approach to Library Management (London: Aslib, 1974), p.3.

11. See, for example, Chris Argyris, Integrating the Individual and the Organization (New York: Wiley, 1964); Frederick Herzberg, Work and the Nature of Man (Cleveland: World Publishing Co., 1966); Rensis Likert, The Human Organization: Its Management 
and Value (New York: McGraw-Hill, 1967); Douglas McGregor, The Human Side of Enterprise (New York: McGraw-Hill, 1960).

12. See, for example, Klaus Musmann, "SocioTechnical Theory and Job Design in Libraries," College \& Research Libraries 39:20-28 (Jan. 1978); Charles Martell, “Administration: Which Way-Traditional Practice or Modern Theory?" College \& Research Libraries 33:104-12 (March 1972); Dougherty, "Human Side of Library Effectiveness"; Maurice P. Marchant, "Participative Management as Related to Personnel Development," Library Trends 20:48-59 (July 1971).

13. See, for example, S. Terreberry, "The Evolution of Organizational Environments," in F. E. Kast and J. E. Rosenzweig, eds., Contingency Views of Organization and Management (Chicago: Science Research Associates, 1973), p.81-100; F. E. Emery and E. L. Trist, "The Causal Texture of Organizational Environments," in Frank Baker, ed., Organizational Systems: General Systems
Approach to Complex Organizations (Homewood, Ill.: Richard D. Irwin, 1973), p. $165-77$.

14. For further discussion of these criteria and their relation to libraries, see Beverly $P$. Lynch, "The Academic Library and Its Environment," College \& Research Libraries 35:126-32 (March 1974); W. Boyd Rayward, "Libraries as Organizations," College $b R e$ search Libraries 30:312-21 (July 1969); Arthur M. McAnally and Robert B. Downs, "The Changing Role of Directors of University Libraries," College \& Research Libraries 34:103-25 (March 1973); Jeffrey A. Raffel, "From Economic to Political Analysis of Library Decision Making," College \& Research Libraries 35:412-23 (Nov. 1974).

15. Pauline Wilson's book A Community Elite and the Public Library: The Use of Information in Leadership (Westport, Conn.: Greenwood, 1977) is one interesting example of such a study. 